\title{
Sofia Coppola e Marie-Antoinette: o rococó na visão contemporânea
}

\section{Maria Cristina Mendes}

\section{Resumo:}

Esse artigo trata da relação entre o filme Maria Antonieta e o estilo Rococó. Numa retomada contemporânea, a diretora Sofia Coppola propõe uma nova leitura estética para esta escola artística considerada por alguns críticos como Barroco tardio. A trilha sonora pautada nos anos 1980 introduz no filme uma ambientação mais familiar ao público de massas. Ancorada na atuação da atriz Kirsten Dunst emerge um novo olhar sobre a personalidade da delfina. As relações com a Pop-art também contribuem para a identificação do público com a narrativa.

\section{Palavras Chave:}

Comunicação, cinema, arte, sociedade, cultura.

\begin{abstract}
:
This article deals with the relationship between the film Marie Antoinette and the Rococo style. In a contemporary point of view, the director Sofia Coppola offers a new perspective for this aesthetic school, considered by some critics as the late Baroque period. The soundtrack based in songs of the 1980`s presents a familiar setting to a massive audience. Anchored in the performance of the actress Kirsten Dunst, emerges a different way of looking at the personality of the dauphine. Relationships with Pop Art help the public to identify themselves with the narrative.
\end{abstract}

\section{Keywords:}

Communication, movies, art, society, culture.

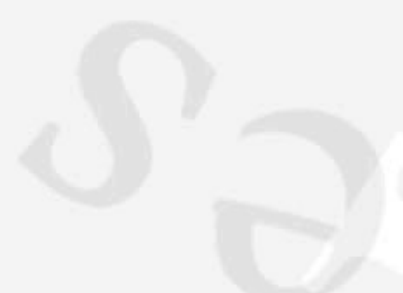

O filme Marie-Antoinette (1), dirigido por Sofia Coppola, torna mais complexa a visão de superficialidade que costuma identificar as atitudes da nobreza francesa do Século XVIII. Lançado no Festival de Cannes de 2006, ele dividiu a opinião do público por evidenciar um lado desprezado pela história oficial, que costuma priorizar, não sem razão, os ganhos da Revolução Francesa. Longe de parecer uma arrogante aristocrata, a jovem monarca é representada como uma adolescente que enfrenta o desafio de abandonar sua vida na Áustria para casar-se, em 1774, com Luís XVI, sem saber se algum dia voltaria a rever sua terra natal. O curso da narrativa, ao justapor distintos estilos artísticos, faz com que o tempo perceptivo do observador seja sugado para dentro da história. Por outro lado, ao estruturar a 
atmosfera fílmica no clima da pop art, lança-se um olhar contemporâneo sobre o passado; a trilha sonora, com canções extraídas dos anos 1980 e a inserção do tênis all-star, criam uma Delfina cuja imagem corresponde, em ampla escala, à veiculação midiática das pop-stars da atualidade. História e ficção são imbricadas numa trama que enfatiza as passagens e as resistências dos estilos artísticos, das estruturas políticas e dos modos de vida.

Sem ficarmos atados às questões evidentemente feministas presentes neste filme, e sem que isso represente algum desprezo pelo assunto, a atenção desse artigo se volta especificamente para a riqueza visual da película, expressa na citação cuidadosa dos movimentos artísticos da história da arte. O estilo pop, aqui abordado nos parâmetros da arte surgida na Inglaterra e difundida nos Estados Unidos nos anos 1960, pode ser percebido através da intensidade da cor e no trato da imagem como um bem de consumo. O consumismo característico da sociedade capitalista, o prazer advindo da aquisição de bens materiais, seja como compensação de um vazio existencial, ou como modo de aproveitar a vida, tem nas cenas das compras de Maria Antonieta, especialmente na variedade dos sapatos e roupas, uma sedução inegável. Coppola estabelece com o público uma identificação com a rainha da França, agora vista como um ser humano mais próximo dos nossos julgamentos éticos contemporâneos. Hoje sabemos que conceitos como verdade ou justiça são complexos ou inapreensíveis em seu todo. Se Maria Antonieta foi uma vilã histórica por mais de duzentos anos, é graças à adaptação cinematográfica do livro de Antonia Fraser que a jovem monarca consegue sua redenção.

Para que o conceito da pop art, enquanto movimento artístico possa ser mais bem compreendido, as palavras de Argan são esclarecedoras:

A Pop-Art, em suma, assinala o ponto de chegada do processo de degradação e dissolução do objeto enquanto termo individualizado num dualismo cognitivo, em que o outro termo é o sujeito, a pessoa: naturalmente, é também a degradação da pessoa enquanto sujeito, cuja atividade pensante fundamental consiste em pôr as coisas como diferentes de si, como objetos. Visto que o objeto é sempre um "distinto" no contexto do real, a regressão do objeto a coisa comporta uma condição de indistinção e, portanto, a regressão da noção distinta de espaço à noção indistinta de ambiente. É, pois, o fim ou a negação radical da concepção humanista, para a qual a arte era distinção entre sujeito e objeto e definição de sua relação ao mesmo tempo espacial e dialética (ARGAN, 1992: 579).

Esta é a atmosfera que vigora na produção de Coppola Uma definição radical da linguagem do filme pode, sem dúvida, afirmar, com segurança, que ele é pop. Um olhar mais atento verifica que, através de uma abordagem pop, Sofia Coppola transita pelos movimentos artísticos que se referem ao período histórico abordado, bem como lança mão do repertório artístico posterior ao enredo numa narrativa que, constantemente, devolve o espectador para seu tempo presente.

As tradições renascentistas presentes na arquitetura, a decoração barroca e os detalhes do rococó são passagens no tempo. Com referências extraídas do repertório da pop art, bem como com a possibilidade de integração de diversos estilos artísticos, o filme trata, acima de tudo de passagens, fato verificável não apenas nos estilos abordados, mas presente também na quantidade de portas que invadem a seqüência fílmica. Passagens no tempo que remetem a um labirinto que não apresenta saída. Entre a profundidade característica deste labirinto e o plano da superfície, a corte francesa, representada no olhar feminino, dialoga com o observador. Estão presentes no filme, também, a ousadia e o enfrentamento difundido pelas técnicas da pintura impressionista. Maria Antonieta, na cena em que repousa no divã, após desfrutar dos prazeres da carne, lança um olhar desafiador em direção ao espectador, tal qual Olympia, personagem da pintura de Edouard Manet, executada em 1865, que influenciou fortemente o surgimento do impressionismo.

Ao analisar a relação entre a pop art e o cinema, não como citação, mas como construção pop de um imaginário cinematográfico, Luiz Renato Martins, enfatiza que na mudança das décadas de 1950 para 1960, “...a mercantilização e a coisificação se convertem na forma geral da experiência" (MARTINS, 1996: 320). O filme Maria Antonieta traz novamente à tona esta noção de consumo e sua imagem remete ao universo artístico e midiático de Andy Warhol ou Oldenburg. Ainda de acordo com Martins, a pop art:

Pressupõe uma produção extensa de bens de massa em face da qual o consumo está implantado 
como hábito majoritário e expressa os valores de uma nação vitoriosa. (...) Por fim, sua referência não é a incerteza da sobrevivência nas sociedades periféricas, mas a rotina do consumo e do lazer em que se mesclam expectativas padronizadas, tédio e entretenimento (MARTINS, 1996: 320).

Maria Antonieta é pop em seu modo superficial de abordar a vida, na sua forma moderna de consumir os bens mundanos. Mas este pop também é uma revisitação, uma citação a mais no hibridismo que compõe o filme.

O período que se passa dentro do castelo de Versalhes, após o casamento, mostra um cotidiano ao mesmo tempo superficial e repleto de informações, características dominantes no modo rococó de interpretar o mundo. $\mathrm{O}$ interesse específico pela análise do rococó neste filme provém do fato que, do mesmo modo pelo qual Maria Antonieta foi considerada uma vilã histórica, também o estilo rococó é visto como um movimento de pequena repercussão nos livros que analisam a história da arte. Esta aproximação entre os conceitos da pop art e o rococó, evidenciada por Coppola, funciona também como um instrumento de revalorização e divulgação de uma escola artística, num novo olhar tanto para a imagem da Delfina como para a arte de seu tempo.

Estas passagens entre um e outro estilo são uma constante nesta produção cinematográfica. Uma cena específica, entretanto, confirma este conceito de passagem e de mudança que são explicitados no transcorrer do filme: a jovem de quatorze anos tem que abandonar tudo que é seu, suas posses e seus afetos. Logo no início da narrativa fílmica, após a negociação do matrimônio, Maria Antonieta, interpretada por Kirsten Dunst, parte de Viena para a França. Na fronteira entre os dois países, ela abandona suas serviçais, seu cachorro de estimação e suas roupas. A futura rainha da França, de acordo com os costumes de então, abre mão do seu passado.

Cria-se um ritual repleto de sutilezas. Geograficamente, a personagem sai da Áustria e entra na França; sua entrada, contudo, em uma tenda especialmente construída para o evento, altera o sentido do movimento de entrar e sair: ela entra na Áustria e sai na França. Existe aí uma inversão do sentido espacial. Esta fronteira dilatada, este espaço que não é nenhum dos dois países, e ao mesmo tempo pode ser ambos, é onde o passado e o futuro dialogam, onde um ciclo se fecha para que outro tenha início. As passagens costumam ser difíceis para a construção dos processos narrativos, pois elas implicam definição de limites e possibilidades de relações. Neste caso específico, a fronteira, o lugar da transformação, se torna espesso como uma bolha entre dois diferentes mundos; é um lugar de iniciação onde jamais se retornará, dado o caráter transitório da construção. Neste não-lugar a arquiduquesa deve aprender os novos códigos sociais.

Dentro deste espaço, Maria Antonieta é despida. A tenda assume por alguns minutos o papel da casa. Gaston Bachelard, ao analisar uma poesia de Milosz, tece uma reflexão sobre nossas moradas a qual se aplica bem a este caso: "De refúgio, fez-se reduto. A choupana se transformou num castelo forte da coragem para o solitário que deve aí aprender a vencer o medo. Tal morada é educadora" (BACHELARD, s/d: 49). E assim se porta a futura rainha da França. Esta passagem pelo abrigo temporário dramatiza o enredo do filme, pois se trata do momento em que a identidade da Delfina começa a ser moldada nos novos padrões sociais.

A representação da cena de nudez é triste; denota a impossibilidade de proteção, da salvaguarda do corpo como espaço pertencente ao ser que o habita. Mas a dignidade da personagem, isto não lhe é roubado. É possível, nesse momento, traçar um paralelo entre sua altivez e as esculturas do período clássico grego ou romano. Vista de costas, meio ao longe, ela poderia ser confundida com alguma escultura de mármore mantida numa sala de museu. Um frame desta imagem pode remeter a um bom trabalho fotográfico de arte contemporânea. Iluminada por uma luz barroca Maria Antonieta submete-se ao escrutínio das mulheres que a vestem, rapidamente, com os trajes franceses. O branco e o azul acinzentado dominam a decoração e as roupas desde a partida da casa da mãe até a entrada em solo francês. Seguindo o roteiro cromático de Coppola, se a personagem sonha em rosa e branco, o mundo é representado em azul e dourado. Os primeiros tons vermelhos aparecerão na roupa daquela que lhe orientará como agir, um alerta cromático da produção do filme, solicitando constantemente nossa atenção para os padrões da corte de Luís XV. 
Este ritual de passagem, com seu clímax no despojamento das vestes, se amplia em nossa percepção pela lentidão silenciosa da cena. O contraste entre a tonalidade escura do abrigo e a palidez do corpo é potencializado pela luz natural que invade o interior da tenda a partir de sua saída/entrada principal. A luz francesa para a qual a futura rainha se dirige é aberta e conduz o pensamento à plenitude de possibilidades da luz do dia. Os cortes que constroem a cena são capazes de desencadear um sentimento de identificação com o espectador. O constrangimento do corpo exposto nos devolve para nós mesmos, para as percepções comuns aos seres humanos de várias épocas ou lugares. Um corpo nu costuma pertencer a alguém que abriu mão de suas defesas. As roupas nos protegem, nos identificam. A diretora do filme cria, neste momento, um forte vínculo com seu público:

Vincular-se (diferentemente de apenas relacionar-se) é muito mais do que um mero processo interativo, porque pressupõe a inserção social e existencial do indivíduo desde a dimensão imaginária (imagens latentes e manifestas) até às deliberações frente às orientações práticas de conduta, isto é, aos valores. A vinculação é propriamente simbólica, no sentido de uma exigência radical de partilha da existência com o Outro, portanto dentro de uma lógica profunda de deveres para com o socius, para além de qualquer racionalismo instrumental ou de qualquer funcionalidade societária (CABRAL, 2006: 93).

Maria Antonieta entra em solo francês com a solidariedade da platéia. De acordo com as afirmações de Steve Coogan, ator que faz o papel do embaixador da rainha na França, gravadas nos special features do DVD, a personagem histórica foi uma vítima da má propaganda, e é em direção a estes equívocos históricos que o roteiro do filme caminha. A suntuosa cerimônia do casamento e o subseqüente ritual do leito de núpcias demonstram o drama que a protagonista enfrentará. O constrangimento advindo da cena de nudez na manhã posterior às bodas, com sua extensão protocolar, justifica, para o público, uma compensação afetiva adquirida nas festas e exageros da jovem monarca. Aos olhos do observador, a aceitação passiva do casamento não consumado transforma a Delfina em alguém que luta para não se deixar abater pelas adversidades da vida.

O barroco, explicitado, também, na narração da mãe de Maria Antonieta, dá início ao filme e ressurge nos momentos em que uma maior dramaticidade é enfatizada: a rainha precisa gerar herdeiros. $\mathrm{O}$ rococó evidencia a busca do conforto cotidiano e a aquisição do prazer advindo da percepção do tempo presente. Os dois estilos se intercalam sobre os pilares da espacialidade criada a partir da perspectiva clássica do renascimento. Enquanto o barroco, mesmo que pautado no trato excessivo da superfície remete a uma profundidade, o rococó permanece na superfície, no momento presente, afastado do afã de preconizar o futuro ou se debruçar sobre o passado.

Após a intensidade barroca, a superficialidade do rococó é um constante desafio para a análise de imagens. A Revolução Francesa contribuiu sobremaneira para que as características da arte produzida nos reinados de Luís XV e Luís XVI - sinônimos para o Rococó - fossem menosprezados. Janson postula que este movimento apresenta "um requinte em tom menor do Barroco curvilíneo..." (JANSON, 1984: 540). Percebe-se, claramente nesta sua afirmação, uma desvalorização da estética do período.

Afirmar que o estilo rococó é uma mera continuação do barroco é desprezar algumas características fundamentais para a compreensão da arte moderna, ou seja, sua ênfase na especificidade do plano pictórico. A superfície, não mais vista tal qual uma janela para o universo das virtualidades este é o paradigma da perspectiva renascentista - mas como uma imagem em contato com o mundo das coisas, é uma construção visual conceitualmente distinta dos moldes anteriores. O espaço teorizado por Alberti (2), monocular e em concordância de coordenadas geométricas, gera a partir das leis de Euclides um modo de medir o mundo. De acordo com Pierre Francastel, entretanto;

O espaço não é uma realidade em si, da qual somente a representação é variável segundo as épocas. O espaço é a própria experiência do homem. É tão-só porque séculos de convenção habituaramnos a aceitar determinados signos expressivos utilizados na educação, com o fito de desenvolver simultaneamente nossas faculdades matemáticas e nossas faculdades visuais, que nos parece evidente que determinada perspectiva euclidiana fornece-nos, de modo espontâneo, a ilusão perfeita da realidade (FRANCASTEL, 1990: 24).

O estilo barroco vai introduzir nova dinâmica ao modelo renascentista, sem, contudo, alterar seu 
modo de medir o mundo. É a mesma configuração espacial, não mais vista frontalmente (tendo o homem como o centro do mundo), mas percebendo o espaço do humano em sua órbita junto aos diversos movimentos do universo que rege a estética dramatizada do barroco. A ordem clássica do renascimento é dinamizada por um espaço onde a luz é mais humana que divina, ou, pelo menos, é compreendida por um olhar que tenta explorar os mistérios desta luz. É a diferença entre o espaço medido pelas distâncias entre os objetos ou figuras de Leonardo da Vinci e o espaço criado pela atuação da luz nas pinturas e gravuras de Rembrandt. São, no entanto, os pintores Antoine Watteau (1684 / 1721) e Honoré Fragonard (1732 / 1806) que enfatizarão a dimensão planar da pintura francesa; esta mudança radical na concepção do espaço representativo representa a força do estilo rococó. Do francês rocaille, que significa "concha", cria-se uma arte da nobreza, a manifestação de um mundo que está para ser destruído.

O rococó representa, portanto, muito mais do que uma vertente menor do estilo barroco. Esta atenção para com a superfície da representação presentes tanto no estilo rococó como na arte pop, lembram que um olhar para o espaço virtual pode, eventualmente, ser menos necessário do que um olhar para as coisas do mundo. Este conceito, numa tela de cinema, onde a inserção do observador é vital para a construção da fábula pessoal, cria uma situação paradoxal: no constante diálogo entre profundidade e superfície, simultaneamente entramos e saímos da narrativa fílmica. Mais uma vez estamos no reino das passagens: passagens de estilo, passagens de percepção e passagens pelas portas que surgem constantemente no filme para criar a dinâmica dos acontecimentos.

A grandiosidade barroca de Versalhes tinha saído de moda no começo do Século XVIII, a favor dos efeitos mais delicados e íntimos do rococó de Watteau. De acordo com a análise que ele faz das pinturas do período,

Ele [Watteau] começou a pintar suas próprias visões de uma vida divorciada de todas as privações e trivialidades, uma vida fictícia de alegres piqueniques em parques de sonho onde nunca chove, de saraus musicais onde todas as damas são belas e todos os enamorados graciosos, uma sociedade em que todos se vestem de refulgentes sedas sem ostentação, e onde a vida dos pastores e pastoras parece ser uma sucessão de minuetos (GOMBRICH, 1972: 358).

Sobre a pintura Festa num parque, executada em 1718, o autor afirma que "há um toque de tristeza nessas visões de beleza que é difícil descrever ou definir, mas que eleva a arte de Watteau além da esfera da simples habilidade e da boniteza" (GOMBRICH, 1972: 59). Nesta produção cinematográfica, o Estilo Rococó recebe uma leitura atenciosa e digna de ser pontuada.

As estratégias utilizadas pela equipe de produção, como pode ser visto nos extras do DVD, recorrem à pesquisa da expressão artística da época e incluem aspectos estilísticos distintos. No início do filme, a atmosfera oscila entre o classicismo arquitetônico e uma dramatização barroca; a iluminação em diagonal, ao banhar as figuras com densas sombras, garante a tensão necessária ao estilo. Na seqüência fílmica, durante o período em Versalhes, uma mistura de barroco e rococó impera na exuberância de detalhes: as roupas, as perucas, a decoração dos interiores bem como as atitudes da nobreza, evidenciam o pensamento vigente no período.

K. K. Barrett, designer de produção, é quem coloca em cena a intrínseca graciosidade do rococó. As cores primárias se transformam em tons pastéis e o estudo das relações cromáticas estrutura uma narrativa tonal. As cores rebaixadas, dominantes nos trajes da nobreza, compõem quadros de uma beleza estética adquirida na compreensão da vida do século XVIII. Às jóias e perucas somam-se a abundância de doces e bolos que inundam a tela. O vestuário, ao encargo de Milena Canonero, une o desconforto do espartilho e das famosas anquinhas. A trilha sonora do filme, que valoriza Vivaldi e o rock dos anos 1980, atualiza este rococó, mostra ao público contemporâneo algumas das ressonâncias estilísticas que permeiam nossas vidas, devolve-nos nossa própria superficialidade e desejo hedonista de convívio com o mundo.

Os cortes das cenas e as passagens entre uma cena e outra trazem o espectador de volta para seu próprio corpo e tempo. As portas, já mencionadas, são muitas e enfatizam constantemente a discussão entre plano e profundidade. A inserção de objetos aparentemente inadequados, como o tênis all-star jogado por entre as compras da rainha, fortalecem esse recurso poético e fazem com que o filme seja 
muito mais do que uma mera narrativa histórica ou biográfica. Coppola não quer criar uma ilusão de realidade para o passado; ela revisita este passado com uma consciência do presente.

Quando Maria Antonieta se muda para o Petit Trianon, palacete que lhe foi dado de presente pelo marido após o nascimento da filha, suas roupas e cabelos se tornam menos exagerados, a peruca alta dá lugar a um penteado solto, num estilo mais prático para a jovem mãe que deseja criar a filha junto da natureza. As flores são plantadas e colhidas pelas duas, galinhas e patos circulam pelos caminhos num lugar que equivale à construção de um novo paraíso. A paisagem, que no desenrolar do filme não tinha atingido sua plenitude, assume seu papel histórico:

Onde ocorre a paisagem? As paisagens não formam, no seu conjunto, uma história e uma geografia. Seus limites são indefiníveis, não têm localização, hierarquia nem centro. De que forma então apontar o sopro que abala o espírito, quando chega a paisagem? Sua força se faz sentir pelo fato de interromper as narrações. Em vez de contar, apresentar. Mas como sem falar de como e quando se chegou - os acontecimentos, a ação? A narração faz correr o tempo, a paisagem o suspende. A poesia então nasceria da compreensão desta incapacidade das palavras darem conta da paisagem. Ela torna disponível à invasão das nuances, torna passível ao timbre: é a escrita desta descrição impossível (PEIXOTO, 1996: 297).

No Petit Trianon, Maria Antonieta se aproxima de liberdade de viver como ela quer e ser aquilo que ela é. Independentemente das solicitações constantes da sociedade, ela busca a simplicidade da vida. Mais uma vez, estabelece-se uma correlação entre o tempo passado e o presente. Hoje a mídia veicula constantemente a possibilidade de um aumento na qualidade de vida diante de um convívio mais próximo à natureza. Assim como muitas pessoas se afastam das grandes cidades para obter uma vida tranqüila, também a Delfina da França se retira de Versalhes para poder educar sua filha com mais dedicação.

A sequiência do filme se direciona, claramente, para uma abordagem suavizada do rococó, agora percebido como uma passagem para os destinos neoclássicos e românticos da arte francesa. Numa continuidade narrativa, o ritmo se desacelera e conduz as transposições estilísticas, ao mesmo tempo em que mantém características contemporâneas na montagem do filme. Estas características, agora, são muito mais da ordem do clima fílmico, do que de uma excessiva preocupação formal. Num ambiente mais acolhedor, novamente nos identificamos com a jovem mãe.

Ao construir sua Maria Antonieta, Sophia Coppola simultaneamente demonstra riqueza no tratamento da superfície e esvaziamento da profundidade. Encontramos aspectos que são comuns tanto ao período Rococó como ao nosso mundo contemporâneo. Temos algo que nos conecta e que merece ser objeto de análise. Este é um aspecto importante da produção do filme: mostrar que as discussões não se esgotam facilmente e que sob a roupagem de valores antigos, muitos deles ainda sobrevivem. Sabe-se que o problema entre profundidade e superfície foi, durante muito tempo e especialmente durante o movimento modernista, um desafio teórico e prático. No mundo contemporâneo, esta complexidade é absorvida, digerida e constantemente reorganizada.

O filme Maria Antonieta, na medida em que questiona nosso parecer histórico e mostra sua humanidade, dá um grau maior de complexidade a uma verdade antes considerada inequívoca. Resgata um aspecto engavetado na história das conquistas ocidentais e nos faz perceber a impossibilidade de um diagnóstico definitivo de compreensão do mundo. Neste século XXI, quando a sociedade vive sob a égide da somatória das contradições e desiste de encontrar uma resposta inequívoca para suas indagações, Edgar Morin esclarece que "A epistemologia complexa toma forma a partir do conhecimento do conhecimento, que compreende o conhecimento dos limites do conhecimento... O conhecimento é sempre tradução e construção" (MORIN, 2003: 200).

Nesta tradução e construção de uma nova imagem pública para Maria Antonieta, Sofia Coppola lança dúvidas sobre uma visão de mundo, problematiza os fatos históricos e lança luz à sensibilidade humana. A esposa de Luís XVI, acusada de extrema frivolidade e arrogância é desmistificada e humanizada. Ao terminar o filme, nos deparamos, uma vez mais, com a impossibilidade de compreensão da verdade. Ao mesmo tempo, percebemos que versões contemporâneas dos fatos históricos são relevantes para um processo contínuo de repensar a vida e conhecer um pouco mais sobre o mundo e 
sobre cada um de nós. A possibilidade de identificação com as injustiças históricas nos torna mais prudentes sobre os próprios pareceres em relação aos fatos do mundo. Humanizar Maria Antonieta permite que cada um de nós, do mesmo modo, se torne mais humano.

Talvez por isso a diretora nos poupe da violência que se sucede à tomada da Bastilha. Coppola nos mostra uma mulher que se recusa a abandonar o marido e segue com ele e os filhos para o destino que previamente conhecemos. As despedidas foram silenciosas, assim com em silêncio está o palácio saqueado e vazio da última cena.

Entre o romantismo e o neoclássico, Sofia Coppola opta por um final que mais se assemelha a Gericault e Delacroix do que a Ingres ou David. A raiz do romantismo, hoje banalizada pelo cinema de massa de Hollywood, readquire seu poder dramático apenas para deixar no ar a parte mais difundida da história de Maria Antonieta. Jamais veremos, seguindo os olhos de Coppola, a Delfina ser decapitada. Ela opta por priorizar justamente os aspectos históricos que foram desprezados ao longo da história, numa abordagem incômoda para seguidores do idealismo revolucionário. O palácio vazio mostra um estilo de arte que foi praticamente varrido da história, condenado por ser um movimento supérfluo e sem profundidade. O caminho onde a pop art rejeitava o aprofundamento existencial do expressionismo abstrato norte-americano e buscava exatamente operar diante da superficialidade das coisas do mundo continua a ser valorizado.

Ao mesmo tempo em que o filme de Coppola é um alerta à aceitação simplista de uma visão histórica parcial, ele também opera como um dispositivo para a manutenção de nosso apreço pela história da humanidade. Dentre os procedimentos culturais que possibilitam um pensamento distinto sobre o repertório histórico de nossa civilização, o cinema funciona como um veículo fundamental para o trânsito das informações.

Além da possibilidade de cumprir um papel antes destinado apenas ao ensino formal, o filme Maria Antonieta de Sofia Coppola é uma aula de história da arte contemporânea, onde o hibridismo estilístico se estrutura adequadamente. A relação estabelecida entre a pop art e o rococó (2 0, enfatizando a presença deste estilo em toda a vida da corte francesa, assume então, a qualidade de abrir-se para uma pesquisa mais atenta. Longe de tecer qualquer conclusão sobre o assunto, este artigo se concentrou justamente, numa reflexão sobre estas relações. Manteve-se a atenção nas portas que se abrem para a superficialidade do rococó no olhar contemporâneo.

\section{Bibliografia:}

ARGAN, Giulio Carlo. Arte moderna. São Paulo: Companhia das Letras, 1992.

BACHELARD, Gaston. A poética do espaço. Rio de Janeiro: Livraria Eldorado Tijuca, s/d.

CABRAL, Muniz Sodré de Araújo. Estratégias sensíveis: afeto, mídia e política. Rio de Janeiro: Vozes, 2006

EAGLETON, Terry. A idéia de cultura. São Paulo: Unesp, 2005.

FRANCASTEL, Pierre. Pintura e Sociedade. São Paulo: Martins Fontes, 1990.

HALL, Stuart. A identidade cultural na pós-modernidade. Rio de Janeiro: DP\&A, 2006.

JANSON, H. W. História da arte - Panorama das artes plásticas e da arquitetura da pré-história à atualidade. Lisboa: Fundação Calouste Gulbenkian, 1984.

MARTINS, Luiz Renato: "Cinema e Pop Art - O flaneur, a prostituta e a montagem". In: XAVIER, Ismail (org.). O cinema no século. Rio de Janeiro: Imago, 1996.

MORIN, Edgar. Meus demônios. Rio de Janeiro: Bertrand Brasil, 2003.

PEIXOTO, Nelson Brissac. "Cinema e pintura - a pintura, a fotografia, o cinema e a luz". In: XAVIER, Ismail (org.). O cinema no século. Rio de Janeiro: Imago, 1996. 
SILVERSTONE, Roger. Por que estudar a mídia?. São Paulo: Loiola, 2002.

\section{Filmografia}

Maria Antonieta (Marie-Antoinette). Direção Sofia Coppola. Estados Unidos, Japão e França. Columbia Pictures Corporation e Sony Pictures Entertainment, 2006, 123 min. Drama.

\section{Notas:}

(1) Nas próximas referências ao título do filme será utilizado o idioma português.

(2) Leone Batista Alberti (1404-1472), arquiteto florentino.

\section{Mini Currículo :}

Bacharel em pintura e especialista em história da arte do século XX (Embap-PR), mestranda em Comunicação e Linguagens pela Universidade Tuiuti do Paraná (UTP), professora do curso de Artes Visuais e Tecnologia em Fotografia (UTP). 